\title{
A study on the critical factors of human error in civil aviation: An early warning management perspective in Bangladesh
}

\author{
Md. Salah Uddin Rajib ${ }^{a^{*}}$ and Luo Fan ${ }^{\text {b }}$
}

\begin{tabular}{l}
\hline C H R O N I C L E \\
\hline Article history: \\
Received September 18, 2014 \\
Accepted 15 December 2014 \\
Available online \\
December 182014 \\
\hline Keywords: \\
Critical Factors \\
Human Error \\
Developing Countries \\
Fuzzy evaluation \\
Early Warning Management \\
Bangladesh
\end{tabular}

${ }^{a}$ Assistant Professor, Faculty of Business Administration, American International University, Bangladesh (AIUB), Dhaka -1213, Bangladesh ${ }^{b}$ Professor, School of Management, Wuhan University of Technology-430070, Wuhan, P.R China

\section{Introduction}

Air transport is growing rapidly and according to the information of International Civil Aviation Organization (ICAO), the expected growth rate is $5 \%$ to $6 \%$ over the next two decades. But, civil aviation has to ensure the safety for its customer. It is accepted that the accident at airline industry is more disastrous than any other industry. Like the other industrial sector, sustainable growth is expected in that sector also. A combination of multiple inter-related sequential events and failures are responsible for the civil aviation incidents and accidents, in which human error plays a significant role (Hawkins, 1993). Management of human error is a factor to reduce the accident and to ensure the sustainable development of Airlines. It is agreed that it is unrealistic to treat human and technical factors as independent in incidents and accidents (Isaac \& Ruitenberg 1999). It's hardly possible to identify any factors' responsibility to disaster individually, as disaster is occurred by the combination of various factors (human and technical). Hence, proactive approach has been suggested in many studies

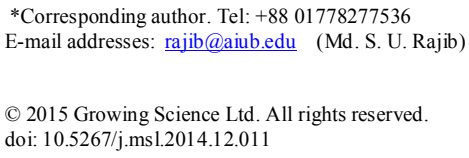


(Maurino, 1999). Consisting with that, this paper aims to find out the critical factors of human error in civil aviation under the perspective of a developing country which is Bangladesh. Moreover, it hopes to represent the scenario of most of the developing countries as well.

It is natural that the entire system's infrastructure - air ports and air traffic control/management together can ensure the aviation safety and consequently can ensure the growth of civil aviation efficiently and effectively. There are different organizations to assess the aviation safety of different countries. The Federal Aviation Administration of USA has categorized the civil aviation of Bangladesh in acceptable category (Knorr, 1997). But, this classification becomes worthless when accident takes place unpredictably. The researchers have also mentioned that the classification contributes little to the improvement of the aviation safety (e.g., Knorr, 1997). Aviation Safety Network states that Biman Bangladesh Airlines records 11 accidents. Among 11 accidents, two are fatal and remaining accidents are non-fatal. The main thing is that the consequences of any fatal accident of civil aviation are irretrievable. Hence, early warning management can play a significant role in civil aviation.

\section{Literature Review}

Human error has been defined in various ways. Swain and Guttman (1983) defined human error as any member of a set of human actions that exceeds some limit of acceptability. Lorenzo (1990) defines human error as any human action that exceeds the tolerances defined by the system with which the human interacts. Reason (1990) defines human error as the failure to achieve an intended outcome beyond the influence of random occurrence. Human error probabilities may assess from actual observation or simulation techniques. Simulation approach considers the dynamic model of the human operator, tasks, and external situational factors (Woods et al., 1987; Cacciabue et al., 1993). Rasmussen (1982)'s identification of multifaceted human error is a highly cited research work. Rasmussen (1982) identified the following multifaceted human error;

\section{Table 1}

Multifaceted human error taxonomy (Adapted from Rasmussen, 1982)

\begin{tabular}{lll}
\hline Factors affecting performance & Operator incapacitation (sickness etc.) & Internal human malfunction \\
\hline Subjective goals and intentions & Intrinsic human variability & Detection \\
Mental load, resources & Mechanism of human malfunction & Identification \\
Affective factors & Discrimination & Decision \\
Task characteristics & Input information processing & Action \\
Physical environment & Recall & External mode of malfunction \\
Work time characteristics & Inference & Specified task not performed \\
Causes of human malfunction & Physical coordination & Commission of erroneous act \\
External events (distraction etc.) & Personal task & Commission of extraneous act \\
Excessive task demand (force, time, & Equipment/procedure design, & Accidentally coincidental events \\
knowledge, etc.) & installation, inspection, etc. & (sneak path) \\
\hline
\end{tabular}

The human error has been classified in different ways. Reason (1990) classified as Behavioral, Contextual and Conceptual. Behavioral error includes formal characteristics (e.g., omission, extraneous etc.), immediate consequences (nature and extent of damage), observability of consequences, degree of recoverability, and responsible party. Casual error addresses the causality by associating human errors with characteristics of the environmental and task context. Conceptual error attempts to establish causality in terms of more fundamental, likely predictable, characteristics of human behavior (Reason, J., 1990). Norman (1981) classifies human error as; 1) slips and 2) mistake. Slips are failures in executing the correct intention and mistakes result from mistaken intentions. Prabhu et al. (1992) organize error shaping factors from the three levels of cognitive control; 1) Skill, 2) Rule and 3) Knowledge. These human errors mainly drive form effects of learning, interference among competing control structures, lack of resources, and stochastic variability. The Human Factors Analysis and Classification System (HFACS) is perhaps the most widely used human factors accident analysis framework. The framework is developed by Shappell and Wiegmann $(2001,2003,2004)$ through their 
research work. There are 4 levels in that framework; Level 1: Unsafe acts of operators - active failures, Level 2: Preconditions for unsafe acts - latent/active failures, Level 3: Unsafe supervision - latent failures and Level 4: Organizational influences - latent failures (Shappell, S.A., 2001, 2003, 2004). Chang et al., (2010) examines human performance factors in air traffic control on the basis of SHEL (Software, Hardware, Environment and Liveware) model. Li Wen-Chin et al. (2008) analyze 41 civil aviation accidents occurred in China, between the years 1999 to 2006 by using the HFACS framework. Their result finds a significant relationship between errors at the operational level and organizational inadequacies at both the immediately adjacent level (Precondition for unsafe acts) and higher levels in the organization (Unsafe supervision and organizational influences). Shappell and Wiegmann (2001, 2003,2004 )'s model has been used in this paper from the perspectives of proactive approaches to attain the objective.

\section{Methodology}

To attain the objective of the paper Shappell and Wiegmann $(2001,2003,2004)$ 's model has been used. One notable thing is that Shappell and Wiegmann state that there is a hierarchical impact in the model i.e., upper levels are proposed to affect the lower levels. This notion has been kept unchanged cautiously in the questionnaire to ensure the quality use of the model. Fig. 1 is the model that has been used to formulate the questionnaire. To cope with the survey environment, technical computing method has been selected for the paper. Fuzzy logic has been used for the paper. Fuzzy logic is the codification of common sense. It enables the appropriate human reasoning capabilities. Fuzzy approach has been combined with the Analytic Hierarchy Process (AHP) developed by Thomas L. Saaty. MATLAB (Version 6.5) has been used to perform the technical computing. The followings are the basic of fuzzy logic that have been used in that research paper;

\subsection{Fuzzy set}

If $\mathrm{X}$ is the universe of discourse and its elements are denoted by $\mathrm{x}$, then a fuzzy set $\mathrm{A}$ in $\mathrm{X}$ is defined as a set of ordered pairs:

$$
A=\left\{x, \mu_{A}(x) \mid x \in X\right\}
$$

\subsection{Factor Selection for the measurement}

Factors have been selected consisting with the adapted model. In model, there are two levels. The first hierarchy factor is $F=\left\{F_{i}\right\},(i=1,2, \ldots \ldots . . m)$, which comes from the second hierarchy factor and $\left\{F_{i j}\right\}$ $(j=1,2, \ldots . n)$

\subsection{Evaluation Index ( $\vee$ ) for the Selected Factors}

Consisting with the objective of the paper, evaluation Index has been formulated. Four different classes have been used in the evaluation scale to identify the critical factors of human error. They are; very highly responsible $\left(V_{1}\right)$, highly responsible $\left(V_{2}\right)$, medium responsible $\left(V_{3}\right)$, and normal responsible $\left(V_{4}\right)$. These classes have been formulated considering the intensity of factors to the human error.

\subsection{Weight (A) Assessment for the Selected Factors}

$1-9$ ratio scale has been used to formulate the decision matrix. Decision Matrix $D$ has been formulated on the basis of the opinion of several experts consisting with the rules of AHP (Analytic Hierarchy Process). Two factors are compared on the same hierarchy model as prescribed by the factor hierarchical division model. Largest Eigenvalue $\left(\lambda_{\max }\right)$ has been used to calculate the Consistency Index 
$(C I)$ and consequently it (largest eigenvalue) has been used in the calculation of Consistency Ratio $(C R)$.

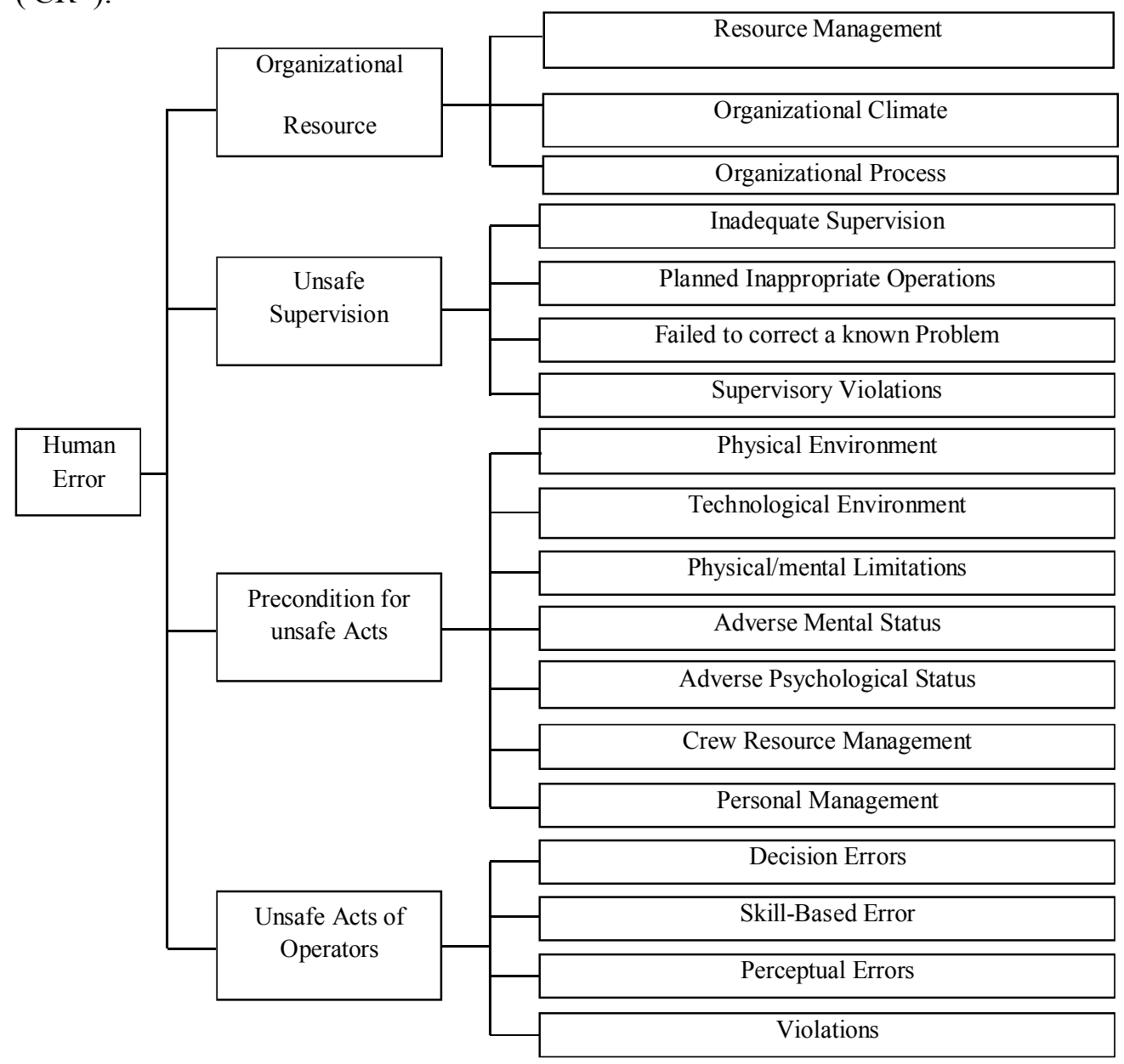

Fig. 1. HFACS, Upper level is proposed to affect the lower levels (Wiegmann \& Shappell, 2003)

\subsection{Factor Evaluation Matrix $R_{i}$}

Evaluation matrix $\left(R_{i}\right)$ has been formulated after collecting the opinion of a group of executives and professional. $r_{i j k}$ is a membership grade that ultimately indicates the degree of evaluation grade. Evaluators' opinion $F_{i j}$ belongs to $V_{k}(k=1,2,3,4) .1,2,3 \ldots \ldots \ldots . . n$ in $R_{i}$ indicates the number of basic factors. $1,2, \ldots . . m$ indicates the evaluation factors i.e., evaluation sets $V$.

$$
R_{i}=\left\{\begin{array}{cccc}
r_{i 11} & r_{i 12} & \ldots & r_{r i m} \\
r_{i 21} & r_{i 22} & \ldots & r_{i 2 m} \\
\ldots & \ldots & \ldots & \ldots \\
r_{i n 1} & r_{i n 2} & \ldots & r_{i n m}
\end{array}\right\} \quad(i=1,2,3,4)
$$

\subsection{Fuzzy Comprehensive Evaluation}

Fuzzy comprehensive evaluation method is started from the lower level to the higher level in a multihierarchy evaluation problem. Fuzzy evaluation set in the second hierarchy: 


$$
B_{i}=A_{i} \times R_{i}=\left(b_{i 1}, b_{i 2}, b_{i 3}, b_{i 4}\right)
$$

where $b_{i k}=\vee_{i=1}^{n}\left(a_{i j} \wedge r_{i j k}\right) \quad(i=1,2,3,4 ; k=1,2,3,4)$

$B_{1}$ has been used to indicate the membership grade of evaluation object $F_{i}$ to evaluation element $V_{k}$ with comprehensive evaluation to each factor $F_{i j}$. After the second level of hierarchy, $1^{\text {st }}$ level of fuzzy evaluation comes in the hierarchy.

$$
\tilde{R}=\left\{\begin{array}{l}
B_{1} \\
B_{2} \\
B_{3} \\
B_{4}
\end{array}\right\}=\left\{\begin{array}{l}
A_{1} \times \tilde{R}_{1} \\
A_{2} \times \tilde{R}_{2} \\
A_{3} \times \tilde{R}_{3} \\
A_{4} \times \tilde{R}_{4}
\end{array}\right\}=\left[R_{i j}\right]_{4 \times 4}
$$

Fuzzy comprehensive evaluation of second hierarchy; $B=A * R=\left(b_{1}, b_{2}, b_{3}, b_{4}\right)$

In which,

$$
b_{k}=\wedge_{i=1}^{n}\left(a_{i j} \wedge r_{i j k}\right) \quad(k=1,2,3,4)
$$

\subsection{Handling the Evaluation Results}

Grade weighted vector has been used to handle the fuzzy evaluation that comes through the AHP approach. The used grade weighted vector is $\mu_{\mathrm{v}}=(1,0.75,0.50,0.25)$. The comprehensive value can be divided into several intervals as $[1,0.75],[0.75,0.50],[0.50,0.25],[0.25,0]$ corresponding to very highly responsible, highly responsible, medium responsible and normal responsible. Calculated comprehensive value into the mentioned intervals represents the visually state of the human error factor. The parameter is a product of weighted vector $\mu_{\mathrm{v}}$ and $\mathrm{B}_{\mathrm{k}}$.

$$
N=\mu_{v} \times B_{k}^{T}=\mu_{v} \times\left(b_{1}, b_{2} \ldots \ldots b_{k}\right)^{T}
$$

\section{Civil Aviation in Bangladesh}

The Civil Aviation Authority of Bangladesh (CAAB) functions as the regulatory body for all aviation related activities in Bangladesh. CAAB is Responsible for safe, expeditious and efficient flow of the air traffic within the Flight Information Region (FIR). CAAB issues the air operator certificate to the qualified airlines in Bangladesh. Apart from the government owned airlines, there are private airlines in Bangladesh certified by CAAB. 'Biman Bangladesh Airlines' is the government owned airlines in Bangladesh. Privately owned airlines of Bangladesh are United Airways, Regent Airways, NovoAir and US-Bangla Airlines. There are 3 international and 5 domestic airports in Bangladesh. About 17 air lines are operating in and out of the country. Bangladesh has bilateral agreements with about 43 states (CAAB , 2012). Previous information indicates that a huge amount is expensed at the repairing and reconstruction of the civil aviation's infrastructures which are damaged by different disasters (Nehal Karim, 1995). Bangladesh experienced only two fatal civil aviation accidents. But the lives of human beings that have been lost are irrecoverable.

\subsection{Survey in Bangladesh}

To identify the critical factors of human error in civil aviation of Bangladesh under the FAHP approach, a questionnaire has been formulated consisting with the Fig. 1. The data has been collected from the CAAB certified airlines personnel (executive level) of Bangladesh. For the basic factor decision, twenty executive opinions have been collected on binary mood. Table 2 represents the statistics of 
decision to identify the critical factors of human error from preconditions for unsafe acts. Statistics of organizational resources, unsafe supervision and unsafe acts of operation has not been presented at there. Table 2 has been presented as an example of mathematical calculation.

Table 2

Critical factors of human error investigation table for Precondition of Unsafe Acts

\begin{tabular}{llcccc}
\hline & & \multicolumn{4}{c}{ Grade } \\
\cline { 3 - 5 } & Element & $V_{1}(\mathrm{VHR})$ & $V_{2}(\mathrm{HR})$ & $V_{3}(\mathrm{MR})$ & $V_{4}(\mathrm{NR})$ \\
\hline 1 & Physical Environment & 9 & 7 & 3 & 1 \\
2 & Technological Environment & 9 & 8 & 3 & 0 \\
3 & Physical/Mental Limitations & 7 & 7 & 5 & 1 \\
4 & Adverse Mental States & 6 & 9 & 3 & 1 \\
5 & Adverse Physiological States & 7 & 9 & 3 & 0 \\
6 & Crew Resource Management & 7 & 8 & 5 & 0 \\
\hline
\end{tabular}

The Evaluation Matrix ( $\left.\tilde{R}_{1}\right)$ has been formulated from the basic matrix (table 2),

$$
\tilde{R}_{3}=\left[\begin{array}{cccc}
0.45 & 0.35 & 0.15 & 0.05 \\
0.45 & 0.40 & 0.15 & 0 \\
0.35 & 0.35 & 0.25 & 0.05 \\
0.30 & 0.45 & 0.15 & 0.05 \\
0.35 & 0.45 & 0.15 & 0.05 \\
0.35 & 0.40 & 0.25 & 0 \\
0.45 & 0.35 & 0.20 & 0
\end{array}\right]
$$

The weights $\left(A_{1}\right)$ has been determined by several experts in terms of 1-9 ratio scale value in decisions matrix $D_{i}$. Decision matrix for precondition of unsafe acts are given as follows,

$$
D_{3}=\left[\begin{array}{ccccccc}
1 & 1 / 3 & 3 & 1 & 3 & 5 & 7 \\
3 & 1 & 5 & 3 & 5 & 7 & 9 \\
1 / 3 & 1 / 5 & 1 & 1 / 3 & 1 & 3 & 5 \\
1 & 1 / 3 & 3 & 1 & 3 & 5 & 7 \\
1 / 3 & 1 / 5 & 1 & 1 / 3 & 1 & 3 & 5 \\
1 / 5 & 1 / 7 & 1 / 3 & 1 / 5 & 1 / 3 & 1 & 3 \\
1 / 7 & 1 / 9 & 1 / 5 & 1 / 7 & 1 / 5 & 1 / 3 & 1
\end{array}\right]
$$

The priority vector has been calculated after the normalization of weight matrix.

$$
\begin{aligned}
& A_{1}=\left[\begin{array}{lll}
0.2828 & 0.6434 & 0.0738
\end{array}\right] \\
& A_{2}=\left[\begin{array}{llll}
0.5193 & 0.2009 & 0.0789 & 0.2009
\end{array}\right] \\
& A_{3}=\left[\begin{array}{lllllll}
0.1878 & 0.3856 & 0.0862 & 0.1878 & 0.0861 & 0.0428 & 0.0237
\end{array}\right] \\
& A_{4}=\left[\begin{array}{llll}
0.3889 & 0.3889 & 0.1535 & 0.0687
\end{array}\right] \\
& A=\left[\begin{array}{llll}
0.0789 & 0.2009 & 0.5193 & 0.2009
\end{array}\right]
\end{aligned}
$$

The calculated consistency ratio is $0.05,0.01,0.04,0.02$ and 0.02 respectively which are below than 
0.1 (C.R <0.1). Hence consistency is acceptable. The fuzzy evaluation of Eq. (5) yields,

$$
\begin{array}{rlrl}
\tilde{B}_{i} & =A_{i} \times \tilde{R}_{i}=\underset{i=1}{\vee}\left(a_{1} \wedge r_{i j}\right) & & \\
& & & \\
\tilde{B}_{1} & =\left[\begin{array}{llll}
0.05 & 0.26 & 0.34 & 0.34
\end{array}\right] & \tilde{B}_{2}=\left[\begin{array}{lllll}
0.05 & 0.23 & 0.36 & 0.35
\end{array}\right] \\
\tilde{B}_{3}=\left[\begin{array}{lllll}
0.40 & 0.40 & 0.16 & 0.03
\end{array}\right] & \tilde{B}_{4}=\left[\begin{array}{llll}
0.02 & 0.20 & 0.44 & 0.33
\end{array}\right]
\end{array}
$$

Now, $\tilde{B}=A^{*}\left[\tilde{B}_{1}, \tilde{B}_{2}, \tilde{B}_{3}, \tilde{B}_{4}\right]^{T}=(0.23,0.31,0.27,0.18)$

Fuzzy evaluation has been corresponds with the different sub-factors systematically. That means $\tilde{B}_{1}, \tilde{B}_{2}, \tilde{B}_{3}, \tilde{B}_{4}$ and $\tilde{B}$ has been corresponds with $F_{1}, F_{2}, F_{3}, F_{4}$ and $F$.

\section{Results/Defuzzification}

Fuzzy comprehensive value has been determined by parametric representation method:

$$
\begin{aligned}
& N_{1}=\mu \times \tilde{B}_{1}^{T}=(1,0.75,0.50,0.25) \times(0.05,0.25,0.34,0.34)^{\mathrm{T}}=0.50 \\
& N_{2}=\mu \times \tilde{B}_{2}^{T}=(1,0.75,0.50,0.25) \times(0.50,0.23,0.36,0.35)^{\mathrm{T}}=0.49 \\
& N_{3}=\mu \times \tilde{B}_{3}^{T}=(1,0.75,0.50,0.25) \times(0.40,0.40,0.16,0.03)^{\mathrm{T}}=0.79 \\
& N_{4}=\mu \times \tilde{B}_{4}^{T}=(1,0.75,0.50,0.25) \times(0.02,0.20,0.44,0.33)^{\mathrm{T}}=0.47 \\
& N=\mu \times \tilde{B}^{T}=(1,0.75,0.50,0.25) \times(0.23,0.31,0.27,0.18)^{\mathrm{T}}=0.64
\end{aligned}
$$

The defuzzificaion shows that the factors of preconditions for unsafe acts are more responsible for human error than the other factors in civil aviation under the perspective of organizational personal information. Organizational resources, unsafe supervision and unsafe acts of operators are in the second, third and in fourth positions respectively.

\section{Conclusions}

The paper has aimed to make the sense about the critical factors of human error in civil aviation in a developing country. The FAHP approach has been used as it is agreed that fuzzy logic helps to code the sense of human beings. The technical computing indicates that taking care is required more for precondition for unsafe acts including strong physical environment, technological environment, handle physical/mental limitations, adverse mental status, adverse psychological status, crew resource management and for personal management to ensure the safety of the civil aviation in Bangladesh, a developing country. Therefore, the analyses urge concentration should be more on the mentioned factors from the concerned authorities. This paper is involved with the determination of critical factors of human error on the basis of information obtained from the organizational personal. In future, alternative sources of information can be used and combined together. It is agreed that the human and technical factors are not independent in any incidents and accidents of civil aviation. Therefore, the contribution from the technical to the human error can be measured in future more keenly.

\section{Acknowledgement}

This paper has been developed at the time of working at the project "Study on Risks Coupling Mechanism of Air Traffic Safety and the Early Warning Decision Support System" supported by National Natural Science Foundation of China (NSFC). 


\section{References}

Cacciabue, P. C., Carpignano, A., \& Vivalda, C. (1993). A dynamic reliability technique for error assessment in man-machine systems. International journal of man-machine studies, 38(3), 403-428.

Chang, Y. H., \& Yeh, C. H. (2010). Human performance interfaces in air traffic control. Applied ergonomics, 41(1), 123-129.

Civil Aviation Authority, Bangladesh (CAAB), Retrieved $8^{\text {th }}$ November 2012 from www.caab.gov.bd. Hawkins, F.H. (1993). Human Factors in Flight, England: Ashgate, Aldershot.

Isaac, R., Ruitenberg, B (1999). Air Traffic Control: Human Performance Factors. England: Ashgate, Aldershot.

Karim, N. (1995). Disasters in Bangladesh. Natural Hazards, 11(3), 247-258.

Knorr, A. (1997). Do "blacklists" enhance aviation safety?. Intereconomics,32(1), 14-22.

Li, W. C., Harris, D., \& Yu, C. S. (2008). Routes to failure: Analysis of 41 civil aviation accidents from the Republic of China using the human factors analysis and classification system. Accident Analysis \& Prevention, 40(2), 426-434.

Lorenzo, D. (1990). A Manager's Guide to Reducing Human Errors: Improving Human Performance in the Chemical Industry. Chemical Manufacturer Association, Washington, DC.

Maurino, D. E. (1999). Safety prejudices, training practices, and CRM: A midpoint perspective. The International Journal of Aviation Psychology, 9(4), 413-422.

Norman, D. A. (1981). Categorization of action slips. Psychological review,88(1), 1.

Prabhu ,P., Sharit, J., \& Drury, C. (1992). Classification of temporal errors in CIM systems: development of a framework for deriving human-centered information requirements. International Journal of Computer Integrated Manufacturing, 5(2), 68 - 80.

Rasmussen, J. (1982). Human errors. A taxonomy for describing human malfunction in industrial installations. Journal of occupational accidents, 4(2), 311-333.

Reason, J. (1990). Human Error. New York: Cambridge University Press.

Shappell, S.A., Wiegmann, D.A. (2001). Applying reason: the human factors analysis and classification systems (HFACS). Human Factors Aerospace Safety, 1, 59 - 86.

Shappell, S.A., Wiegmann, D.A. (2003). A human error analysis of general aviation controlled flight into terrain accidents occurring between 1900 and 1998. Report no. DOT/FAA/AM-03/4. Federal Aviation Administration, Washington, DC.

Shappell, S.A., Wiegmann, D.A. (2004). HFACS analysis of military and civil aviation accidents: a north American Comparison. In: Proceedings of International Society of Air Safety Investigators, Australia, Queensland, 2004, November: $2-8$.

Swain, A., Guttman, H. (1983). Handbook of Human Reliability Analysis with Emphasis on Nuclear Poser Plan Applications. Final Report (NUREG/CR-1278). United States Nuclear Regulatory Commission, Washington, DC.

Woods, D.D., Roth, E.M., \& Pople, Jr. H.E. (1987). Cognitive Systems Engineering: An Artificial Intelligence Spleen for Human Performance Assessment (NUREG-CR-4862). US Nuclear Regulatory Commission, Washington, DC. 